\title{
Higher Education in the Digital Age
}

\section{William G. Bowen}

Princeton, NJ: Princeton University Press, 2013, pp. 172 ISBN 978-0-691-15930-0

doi:10.15179/ces.16.1.7

William G. Bowen is President Emeritus of the Andrew W. Mellon Foundation, former president of Princeton University and founding chairman of ITHAKA. ${ }^{1}$ Over his long career he has enriched academic (and general) community with contributions on topics such as class inequalities in higher education, college sports at all levels, and completion rates in higher education. He also gave a very valuable perspective of what it means to be a president of a major university in Lessons Learned: Reflections of a University President (Bowen, 2010).

In Higher Education in the Digital Age Bowen focuses on two major issues in higher education today: rising cost of attending higher education institutions and resorting to advances in digital technology as a possible way of alleviating this problem. The book is based upon Bowen's lectures "Cost and Productivity in Higher Education" and "Prospects for an Online Fix", given at Stanford University in October 2012. In addition to discussing the main points of these

1 ITHAKA is a non-profit organization aimed at supporting academic community to use digital technologies in advancing their teaching and research in a sustainable way. 
lectures, the book also incorporates comments by carefully selected educators that address specific aspects of online learning.

First part of the book titled "Cost and Productivity in Higher Education" covers the area of productivity and increasing costs in higher education.

"Cost disease" is a term coined by William J. Baumol and Bowen himself in their study of performing arts (Baumol and Bowen, 1966). Basic idea is that “... in labor intensive industries such as the performing arts and education, there is less opportunity than in other sectors to increase productivity by, for example, substituting capital for labor" (p. 3). On the other hand, throughout the economy, wages for roughly homogeneous individuals have to increase at about the same rate, thus making unit labor costs rise faster for performing arts and education. Bowen cites Robert Frank's observation (Frank, 2012: 3): "While productivity gains have made it possible to assemble cars with only a tiny fraction of the labor that was once required, it still takes four musicians nine minutes to perform Beethoven's String Quartet No. 4 in C minor, just as it did in the 19th century".

Bowen acknowledges the complexity of defining productivity in a field such as education. He refers, among other studies, to Jones et al. (2012: 2243) who highlight the problem of productivity missmeasurement since "important dimensions of service output such as accessibility and convenience - factors that are greatly improved by IT - are difficult to quantify and rarely captured by productivity metrics". Consequently, he simply refers to productivity as a ratio of two numbers. Productivity can be improved by measures of either output enhancement (raising the numerator) or input converse (lowering the denominator). In line with Jones et al. (2012) the author also mentions that over the last 25 years IT has made an impact on the numerator (output-enhancing measures) but in a way not captured by productivity measures or costs per student. Furthermore, not all type of output were "hit" the same. IT revolution has had a much more profound impact on research output (introduction of data analyzing software, scholarly infrastructure, advances in communication etc.) 
than on students, whose "chalk and blackboard" class format has not changed much until very recently.

Besides the cost disease, Bowen mentions three additional factors that have also helped push the costs up. The first one is inefficiency in governing day-to-day university activities. Centralizing some functions such as human resources, IT and purchasing at the university level have reduced, or at least slowed down, rising costs. However, Bowen remains cautious not to embrace too much of this "corporate mindset" (p. 10) as it could endanger the quality of teaching. Factors of production in higher education are anything but easily substitutable (for example, highly specialized teaching staff cannot be easily substituted from one class to another). Some of these institutional rigidities are the result of the very nature of an academic enterprise.

Second factor relates to the desire to "buy the best". The US universities are known for their high degree of competitiveness for best candidates and best departments, and although the author admits this to be one of the key reasons why US universities are some of the best in the world, he expresses concerns about increasing stratification among institutions. "Buy the best" mindset puts extra pressure on the not-so-wealthy universities to go overboard on their budget - a cost which is then usually transferred into higher tuition fees.

Third factor Bowen deals with is the supply side problem and mismatching. The author refers to the paper by Bound, Lovenheim and Turner (2010) which shows an increase in the time-to-degree (TTD) over the last three decades (localized among public institutions outside the most selective institutions). Reasons behind this include the decline in public resources and the tendency of students to work more hours for wage. Student attitudes towards graduating on time are another side of the medal. In Crossing the finish line study (Bowen, Chingos and McPherson, 2009: 16) one recent graduate stated that "graduating in four years was like leaving the party at 10:30 p.m.”. An increase in TTD is also caused by 
a large number of students who end up at institutions for which they are not qualified i.e. a miss-match.

First chapter concludes with the discussion on affordability. Baum, Kurose and McPherson (2013) show that in the US state support for colleges and universities fell from 44 percent in 1980 to 22 percent in 2009. The only solution to preserve teaching quality and enrollment numbers was to increase tuitions. Despite this, parents' and students' attitudes towards obtaining a university degree have not faltered. In the most recent Sallie Mae/Ipsos survey (Sallie Mae/ Ipsos, 2013) 85 percent of college students and parents stated that education was an investment into the future. Mitchell (2012) reports that starting from 2010 student debt exceeded credit card debt. Pew Research Centre reported that the average outstanding student loan balance was US\$ 26,682 in 2010 among all households with student debt, with the greatest relative burden of this debt concentrated in bottom fifth on income distribution (Fry, 2012). The question that arises is "What is the right amount of debt a student should take on?" Avery and Turner (2012) explain that much depends on individual talents, choice of major, institution attended, career interests, prospects etc. Their conclusion, however, rejects the claim that student borrowing is too high across the board (with possible exception of for-profit colleges).

Second part of the book "Prospects for an Online Fix" is focused on the potential impact of different approaches to online learning, and whether it can be a "fix" for cost disease.

In 2000 when Bowen gave a lecture at Oxford referring to studies from the University of Illinois and Navarro (2000) he inferred that potential savings from using technology to increase productivity are scarce. Thirteen years later William G. Bowen has changed his stand on this issue. He justifies this "conversion" by improvements in IT such as greater access to Internet, improvements in Internet speed, reduction in storage costs, proliferation of sophisticated mobile devices 
and other technological advances that have paved the way for cost reduction in online learning.

So what has to change to make online learning widely accessible and more accepted by faculty and students? Bowen divided this issue under three headings: lack of hard evidence about learning outcomes and potential savings; lack of shared but customizable teaching and learning platforms; and the need for new mindsets and fresh thinking about models of decision-making.

How effective is online learning in improving learning outcomes, or at least, in maintaining them? Has introduction of online learning led to the reduction of costs per student? Unfortunately, it is still uncertain. Bowen presents the study carried out by ITHAKA to investigate online learning outcomes (Bowen et al., 2012). The study was carried out using Statistics course developed by Carnegie Mellon University, taught in hybrid mode (with one face-to-face Q\&A session per week). Final examination results were compared to students who took classic face-to-face classroom format. Bowen reports two important results. First, there is no statistically significant difference in learning outcomes between students in different class formats; and second, this result is consistent across campuses and subgroups of a sample. What about cost savings? Their results show a 3657 percent savings in compensation costs alone. This result should, however, be interpreted with caution. As Bowen points out "A fundamental problem ... is that contemporaneous comparison of the costs of traditional modes of teaching and of newly instituted online pedagogies are nearly useless in projecting steadystate savings..." (p. 51). Doing anything for the first time is much more costly than repeating the well-established routine. Substantial start-up costs in online learning involve: course development and IT equipment, costs of training personnel for this new mode of teaching, transaction costs of switching to hybrid mode etc. Furthermore, this study involved only one course, in a field well-suited for online learning. Instead of just making a comparison between traditional and online formats of learning, different modes of online learning should also be 
compared. Analysis should also extend to issues of space utilization, capital costs and indirect costs.

For successful implementation of online learning, perhaps the most obvious requirement is customizable, sustainable platform. But how much in-house customization is actually needed? While Bowen acknowledges that "faculty are extremely reluctant to teach courses that they do not own" (Bacow et al., 2012: 21), he makes a case that certain degree of standardization would be beneficial. It would allow for economies of scale of well-developed features of platforms, and additionally, some institutions simply do not have the manpower (or/nor the brainpower) to start from scratch. Also, different platforms will be appropriate for different courses. The notion of a single platform is quite unrealistic and illsuited for all courses (e.g. statistics course has completely different needs than politics course). So, how should such platforms be developed? Bowen sees great potential in collaborative effort within higher education community. Institutions that have shown the capacity (and will) to execute should assume leadership in these enterprises. He primarily sees the leading MOOCs (massive open online courses) as possible leaders. Developers of Coursera, edX, and Stanford's Class2Go already have an impressive infrastructure, a pool of talented people at their disposal, solid financial base and real standing in academic community. The need for customization, however, will continue to be present. The reason why these MOOCs had such success is because the one-size-fits-all policy drove their marginal cost of serving one extra user (student) almost down to zero. It is much more ambiguous how - or even whether - this need of customization for local use would affect cost savings. An alternative option would be to let the free markets provide best platforms suited for individual faculties. The main risk here is that these for-profit organizations might choose to cover their costs by privatizing significant amount of information about how students learn. This information would be highly beneficial to researchers and faculty looking to improve learning outcomes of their students and privatization would harm potential gains in this externality. Educational community should agree about 
how such information depository should be created and maintained, as it would surely serve "in the best interest of the public".

Bowen argues that a new mindset is a prerequisite to overcome barriers to adoption of online learning. Such barriers include fear that online instruction will diminish faculty ranks and the fact that most faculties are alien to this kind of teaching. There is also a grudge of financial pressures that come with the implementation of such programs.

Finally, the author warns us not to overdo online learning and stresses the value of "minds rubbing against minds". Person-to-person and student-teacher communication can serve as inspirational, life-changing experiences. After-class or late-night student exchange can have a profound influence on one's career and worldview. Bowen advocates an adoption of a careful mix of instructional styles. This mix will surely vary from institution to institution, with arts universities adopting more in-person teaching and more quantitative institutions offering more online courses. He also urges to retain the freedom of thought and reminds us that universities should also teach values, as opposed to just knowledge.

Discussion by Howard Gardner: Howard Gardner focuses primarily on the issue of residential education. He stresses the importance of in-person teaching and reflection sessions where many students look for their role models, both in peers and teachers, which can then shape their academic and work career. Next, he moves on to discuss collaboration among higher education institutions. He provides an example of three schools near Cambridge: Wellesley College, Babson College and Olin College who serve as good complements to each other as they all have different foci. In such interdisciplinary environment we stand much better chances of rising up to the issue of sustainability. And the collaboration should not stop there; it should go beyond national borders. Such collaborations, he says, have an important influence on US students by exposing them to different population and cultural setting. The future he would like to see is one where having joint degrees, students work together on global problems 
that require interdisciplinary and intercultural thinking and share resources over long distances. He agrees with Bowen that education should be extended to incorporate teachings of values, as they are the ones that make us human. In conclusion, he leaves us with a thought that technology can provide "the answers to all questions - except the important ones" (p. 106).

Discussion by John Hennessy: Hennessy (re)examines a cost problem in education. His chief concern is the role of financial aids and state subsidies. On one side, financial aid has increased in high-end private institutions as a result of, in accordance with Bowen, increase in the endowment which has grown about 6 percentage points above the higher education price index which is in turn 0.5 to 1 percentage points over the wage inflation index. Public institutions, on the other hand, have seen significant reduction in government subsidies as a consequence of budget cuts. On average, per-pupil funding in these institutions has decreased by 15 percent. Setting aside the negative influence of 2008 financial crisis, Hennessy also points out the quadrupling of spending in Medicaid over the last thirty years, that diverged investment away from education. Future does not look too bright as he sees more and more students paying tuition close to full sticker price. Contrary to general opinion he believes it is not the increase in luxuries at student dorms that drives up sticker prices but rather the changing nature of the student body itself. An increase in psychological support services, community centers and ethnically themed dorms easing the adjustment of foreign students all these factors lead to better learning outcomes, but they also come at a higher cost.

Next, he points to a problem of a growing number of research institutions. Using an example of Berkley University and San Jose State University, where the former is more of a research-oriented institution while the latter is primarily an educational institution, he calculated that cost per student at Berkley is estimated at US\$26,800 per year and at San Jose State US\$11,800 per year. Teacherto-student ratios are 15:1 and 26:1, respectively. He concludes that education in research-oriented institution is much more expensive and, unless some other 
source of income is found (e.g. good will of philanthropists), the US will have to decrease the number of research institutions.

Completion rate for the six-year programs at public universities is about 55 percent while at private institutions it is just over 60 percent. But the consequences of non-completion are even worse. For a student who drops out it is very hard to demonstrate associated competences s/he may have obtained just by being a part of academic community. This extends into discussion about loan burdens and defaults. Increasing costs drive up loan indebtedness and lack of completion leads to greater probability of default. From 2006-2007 to 2008-2009 for-profit default rate went from 9.8 to 15.4 percent.

Discussion by Andrew Delbanco: Delbanco starts off by presenting two photographs from recent magazine covers. The first photograph is a metaphor for public perception that college is "essentially expensive dating service for pampered students" (p. 130). The reality is, however, quite different - about a third of students are adults with families and jobs, who attend underfunded, overcrowded community colleges with no luxuries. Yet the general opinion described by the first photograph prevails, thus leading to lower public support on spending in education and endangering the continuation of program incentives for poor students. The second photograph presents a student who is studying online from his home. Among other things, the most striking feature Delbanco recognizes is the fact that he is alone. Any connection he has with his peers and professors is a virtual one. He comments on a metaphor by Hennessey who said that new technology will hit colleges and universities with the force of a "tsunami", comparing it to early Schumpeterian description of capitalism as "creative destruction". Using online revolution in alleviating cost disease is a good thing, but, on the other hand, "tsunamis are not exactly known for their selectivity" (p. 137).

Online revolution might increase extra institutional affiliations and loyalties of faculty members. It reduces provincialism, dilettantism and institutional 
inbreeding, but it has also helped in elevating some professors to the status of "stars" who demand high fees for their lectures, and some institutions towards making their own rules about teaching loads, business venture etc. He even goes so far as to say that some teaching, like languages, might completely be replaced by technology (for example, French speaking Siri on iPhone).

Delanco's chief concern rests on the educational value of these new online learning technologies. He makes a distinction between the instruction and provocation and (re)states it in many ways: facts versus knowledge, skills versus wisdom, information versus insight... Current US educational system is already moving towards the instruction end of the spectrum, and online technologies would only add momentum to this process. In teaching humanity it makes little sense to categorize classes as "introductory" and "advanced" - the emphasis is, and should always be, on interpretation. Can online education teach both kindness and cleverness? Let's hope so.

Discussion by Daphne Koller: Why is this increase in online learning happening now? Koller claims there has been a shift in educational paradigm, i.e. online learning should not try to simply replicate everything being done in-class, but should move towards developing entirely new platforms and systems of learning. The greatest advancement we can now utilize is the possibility of interaction between students and materials, ruling out passive one-way communication as outdated and unsuited for today's educational needs. She emphasizes that students "rubbing minds" with each other is not endangered - it would be wrong to apply standards and methods of previous generations to this new "cyber" generation. An interaction via electronic media is an indistinguishable part of modern culture, and we should not presume, based on the way we were brought up, that rubbing of minds can only happen face-to-face.

New formats of online learning, which allow for constant feedback to student, are much more interactive than full auditorium of students and one teacher, providing a better chance for completion. Data collected from such feedback, 
generated by almost every click of a mouse is then stored, analyzed, and can be used to further enhance software packages and learning platforms.

Another opportunity presents itself for potential students who have not yet enrolled in higher education or professionals outside academic institutions. MOOCs could provide them with an opportunity to take classes prior to enrollment so they would be well on their way when they actually enroll. Furthermore, they can explore multiple MOOCs to get the general impression of the courses before making a final enrollment decision. This would help increase completion rates and also alleviate mismatch mentioned in Bowen's talk. For professionals this makes lifelong learning more accessible and increases their competitiveness on the labor market. Outcomes may also be improved by allowing colleges to expand their curricula beyond those offered only in-house by offering online courses from other institutions.

Finally, similarly to Gardner, Koller too steps outside US borders by stating that about two-thirds of current MOOC students are from abroad. In this way students and faculty get a perspective of life and culture in the rest of the world which can have a profound influence on their ways of learning and teaching. On a global scale, more educated people would mean fewer problems with hunger, unemployment, extremism and even population explosion.

\section{Final thoughts}

I think the book Higher Education in the Digital Age by William G. Bowen gives a very good description of the basic concepts and issues in higher education. As President Emeritus of Princeton University (1972-1988) and the Andrew W. Mellon Foundation (1988-2006), Bowen speaks with the voice of experience, often illustrating with personal examples from his career. Although online learning can be thought of as relevant worldwide, with the exception of general productivity analysis, this book offers little to scholars outside the US. A deeper study of the materials in the book (and the lectures), together with very informative 
set of endnotes, give a realistic picture of the higher education in the US and its main challenges. This is surely a consequence of the fact that this book started off as lectures given at Stanford University, so Bowen adjusted the material for the audience accordingly. While primarily concentrating on the reasons behind rising costs of higher education Bowen fails to mention some alternative funding models, such as State of Oregon's "Pay it Forward" pilot program which allows students to forego taking out loans and debt, but they agree to pay the state back a small portion of their future income over the course of a couple of decades (White, 2013). Throughout the book, Bowen resists the temptation of explicitly saying that online education can remedy the problems of costs and productivity in higher education, but rather he offers an insight into promising, and still quite unexplored, area for innovation regarding the affordability and merits of higher education. What he sees as particularly promising, and worth pursuing, is the "hybrid" approach, a mix of online learning with typical face-to-face "classroom teaching" sessions. Although he presents some evidence that outcomes would not suffer as a consequence of switching to online learning, he acknowledges that much more empirical testing is required before fully switching to "flipped classroom". He also acknowledges that some areas, like arts and humanities, will never be able to become fully digitized because of the very nature of such programs. Towards the end of the book he urges the public and academic community not to get too carried away by the media frenzy created lately about the use of online learning. Implemented unadvisedly it can certainly bring more harm than merits. Inclusion of comments by other educators and Bowen's replies give an extra value to the book, as it brings forth a sense of academic debate and offers views from a perspective different from Bowen's. These commentators were carefully weighted with Gardner and Delbanco as IT sceptics who emphasize the concepts of value and provocation, Hennessy who stresses out the parallel problems of growing sticker price and student indebtedness, and low completion rates, and finally Koller who speaks of online revolution with unmatched enthusiasm. The mere fact that Bowen decided to finish the book with such captivating talk of benefits of online learning speaks of his preferences as well. Finally, Higher 
Education in the Digital Age is a must-read for all education researchers interested in online learning as it represents a valuable source of both ideas and references for future studies.

\section{Literature}

Avery, Christopher and Sarah Turner, 2012, "Student Loans: Do College Students Borrow Too Much - or Not Enough?”, Journal of Economic Perspectives, 26(1), pp. 1-30. http://dx.doi.org/10.1257/jep.26.1.165

Bacow, Lawrence S., William G. Bowen, Kevin M. Guthrie, Kelly A. Lack and Matthew P. Long, 2012, "Barrier to Adoption of Online Learning Systems in U.S. Higher Education”, http://www.sr.ithaka.org/sites/default/files/reports/ barriers-to-adoption-of-online-learning-systems-in-us-higher-education.pdf (accessed March 6, 2014).

Baum, Sandy, Charles Kurose and Michael S. McPherson, 2013, "An Overview of Higher Education", Future of Children, 23(1), pp. 17-39. http://dx.doi. org/10.1353/foc. 2013.0008

Baumol, William J. and William G. Bowen, 1966, Performing arts-the economic dilemma: a study of problems common to theater, opera, music and dance, New York, NY: The Twentieth Century Fund.

Bound, John, Michael F. Lovenheim and Sarah Turner, 2010, "Increasing Time to Baccalaureate Degree in the United States", NBER Working Paper, no. 15892, Cambridge, MA: NBER.

Bowen, William G., 2010, Lessons learned: Reflections of a university president, Princeton, NJ: Princeton University Press. 
Bowen, William G., Matthew M. Chingos, Kelly A. Lack, and Thomas I. Nygren, 2012, "Interactive Learning Online at Public Universities: Evidence from Randomized Trials", http://www.sr.ithaka.org/sites/default/files/reports/ sr-ithaka-interactive-learning-online-at-public-universities.pdf (accessed March 6, 2014).

Bowen, William G., Matthew M. Chingos and Michael S. McPherson, 2009, Crossing the finish line: completing college at America's public universities, Princeton, NJ: Princeton University Press.

Frank, Robert H., March 10, 2012, “The Prestige Chase Is Raising College Costs", New York Times, http://www.nytimes.com/2012/03/11/business/collegecosts-are-rising-amid-a-prestige-chase.html?ref=todayspaper\&_r=0 (accessed March 6, 2014).

Fry, Richard, 2012, "A record one-in-five households now owe student loan debt" Pew Research Center, http://www.pewsocialtrends.org/files/2012/09/09-26-12Student_Debt.pdf (accessed March 8, 2014).

Jones, Spencer S., Paul S. Heaton, Robert S. Rudin and Eric C. Schneider, 2012, "Unravelling the IT Productivity Paradox - Lessons for Health Care", New England Journal of Medicine, 366(24), pp. 2243-2245. http://dx.doi.org/10.1056/ NEJMp1204980

Mitchell, Josh, May 31, 2012, "Student Debt Rises by $8 \%$ as College Tuitions Climb”, Wall Street Journal, http://online.wsj.com/news/articles/SB1000142405 2702303640104577438252890217584 (accessed March 7, 2014).

Navarro, Peter, 2000, "Economics in the Cyberclassroom", Journal of Economic Perspectives, 14(2), pp. 119-132. http://dx.doi.org/10.1257/jep.14.2.119 
Sallie Mae/Ipsos, 2013, "How America Pays for College 2013: Sallie Mae's National Study of College Students and Parents", https:/www.salliemae.com/ assets/Core/how-America-pays/howamericapays2013.pdf (accessed March 8, 2014).

White, Martha C., July 17, 2013, "Oregon's "Pay It Forward” Program: Imagine College with No Tuition, No Loans, No Debt", Time, http://business.time. com/2013/07/17/oregons-pay-it-forward-program-imagine-college-with-notuition-no-loans-no-debt/ (assessed March 15, 2014).

Bruno Škrinjarić

The Institute of Economics, Zagreb 